\title{
Determinants of long acting contraceptive use among reproductive age women in Ethiopia: Evidence from EDHS 2011
}

\author{
Alemayehu Shimeka Teferra ${ }^{1, *}$, Abebach Asmamaw Wondifraw ${ }^{2}$ \\ ${ }^{1}$ Department of Epidemiology and Biostatistics, College of Medicine and Health Sciences, University of Gondar, Gondar, Ethiopia \\ ${ }^{2}$ Amhara National Regional Health Bearau, Bahir Dar, Ethiopia
}

Email address:

alemayehushimeka@gmail.com (A. S. Teferra), abebech100@gmail.com (A. A. Wondifraw)

To cite this article:

Alemayehu Shimeka Teferra, Abebach Asmamaw Wondifraw. Determinants of Long Acting Contraceptive Use among Reproductive Age Women in Ethiopia: Evidence from EDHS 2011. Science Journal of Public Health. Vol. 3, No. 1, 2014, pp. 143-149.

doi: $10.11648 /$ j.sjph.20150301.33

\begin{abstract}
Introduction: Promotion and utilization of effective and convenient family planning methods in countries with high birth rates and limited resources have a potential to improve maternal and child health. These could reduce the costs of achieving millennium development goals. However, the contribution of long acting contraceptives both female and male sterilization, intrauterine device, and implant in Ethiopia is very low. Thus, the aim of this study was to identify the determinants of long acting contraceptive use in Ethiopia to improve its utilization. Methods: Unmatched case control study design was employed using data from the 2011 Ethiopian Demographic and Health Survey. Questionnaire was used to extract data from EDHS data set. The extracted data was transformed, edited and recoded using SPSS data editor command. Cross-tabulation was used to describe cases and controls. Logistic regression analysis was used to identify the determinants of LACs use. Strength of the association was assessed using odds ratio with $95 \%$ confidence interval. Result: The mean age of cases and controls were $32 \pm 7$ and $31 \pm 9$, respectively. Sixteen seven (18.4\%) of cases have secondary and above level of education. Among the cases, 199 (54.7\%) of them did not want any more children. Fifty four percent of cases were exposed to family planning messages through mass media. Secondary and above level of education $[\operatorname{AOR}(95 \% \mathrm{CI})=3(1.5,5.0)]$, working status of women $[\mathrm{AOR}(95 \% \mathrm{CI})=1.7(1.3,2.2)]$, being visited by family planning workers $[\mathrm{AOR}(95 \% \mathrm{CI})=1.8(1.4,2.5)]$ and exposure to family planning messages through media $[$ AOR $(95 \% \mathrm{CI})=1.5(1.1,2.00)]$ were significantly associated with the use long acting contraceptive. Conclusions and Recommendations: Educational and working status of women, being visited by family planning workers, exposure to family planning messages and wanting no more children have positive association on LACs use. Provision of information about long acting contraceptives using mass media in advance and encouraging women to complete secondary level of education and above were important to improve LACs utilization.
\end{abstract}

Keywords: Long Acting Contraceptives, Ethiopia, Reproductive Age Women, EDHS

\section{Background}

Long acting contraceptives (LACs) are types of modern contraceptive methods which have low failure rate, safer and cost effective than short acting contraceptives. This includes male and female sterilization, implant and Intrauterine devices. These are called long acting contraceptives because pregnancy is averted more than a year in one action without requirement of repeated procedures. Male or female sterilization are permanent and irreversible methods while IUD and implant are reversible because pregnancy can be initiated after removal of these methods (1-6).
Approximately $25 \%$ of women and couples in sub-Saharan Africa who want to space or limit their births are not using any form of contraception (7). More than half of the people in Africa are younger than 25 years old, so unmet need is expected to increase as these individuals enter their reproductive years (8). Over time, the use of LACs has not kept pace with that of short-acting methods, such as oral contraceptives and injectables. Data from demographic and health surveys from four sub-Saharan countries show that the proportion of women currently using LACs is significantly 
lower than the proportion using short-acting methods. In many countries in the region, fewer than $5 \%$ of women who are using contraception are using LACs (9). As a study conducted using demographic and health surveys data in sub-Saharan Africa between 2003 and 2005 showed, more than $20 \%$ of women in nine of the 11 countries surveyed do not want any more children. However, in each of the nine countries, fewer than $7 \%$ of the women are using an LAPM (10). Although short-acting methods provide contraceptive coverage for many women who do not want more children, these women are still entitled to a choice of contraceptive methods. LACs may be a good option for some of them, given their reproductive intentions, but they may not be using one because of lack of knowledge, access or other factors (7).

There is a vast unmet contraceptive need in sub-Saharan Africa, a region that has a high fertility rate coupled with a desire among women to space and limit their number of births (11). Short-term family planning methods have traditionally been used here (12) and long-acting reversible contraceptives methods (LACs) have been under-utilized despite their effectiveness and low cost (13). Access to family planning services in sub-Saharan Africa is especially low among rural, less educated, and poorer women (14).

As these methods are not user dependent, they have very low levels of failure that may lead to unintended pregnancy. However, the region has predominantly relied on short-term family planning methods over the past 30 years. Expanding access to a variety of LACs in sub-Saharan Africa is a key to increasing women's contraceptive choice and addressing the high unmet need, and will contribute towards achievement of the FP2020 goals.

Modern family planning services were initiated in 1966 by the Family Guidance Association of Ethiopia (FGAE) (15). Though it showed many progresses, the overall achievement is insufficient in terms of maternal mortality and contraceptive prevalence rate (CPR). Ethiopia has seen a dramatic increase in CPR over the last decade, from a low of $8.2 \%$ in 2000 to $14.7 \%$ in 2005 and $28.6 \%$ in 2011 - an average increase of $2 \%$ per year. Knowledge of any method of family planning reached at maximum. Ninety seven percent $\&$ $98 \%$ of all women and men reported having heard of at least one modern contraceptive method in 2011 EDHS (16-18).

Despite this gain, the objective of health sector development plan four (HSDP IV) over contraceptive prevalence rate to reach $66 \%$ by the year 2015 may not be attainable (19). As showed in the 2011 EDHS report, the contraceptive method mixes was limited to short acting contraceptives such as Injectables (21\%) and pills (3\%). Only $4.2 \%$ of currently married reproductive age women use LACs (male and female sterilization, IUD and implant). Similarly, there was 9\% unmet need for limiting in 2011 EDHs. This shows the presence of higher unmet need and low utilization of LACs in Ethiopian (18).

Therefore studying the determinants of long acting contraceptive use is a top priority action to improve its utilization. LAC methods are safe, effective and convenient methods of preventing unplanned and unwanted pregnancy.
However, according to EDHS 2011 report the contribution of LACs for contraceptive prevalence rate was very low. Similarly, the same report showed that, there was $9 \%$ unmet need for limiting. However, which factors contribute to the low utilization and higher unmet needs of these methods locally and nationally are not well studied. In addition, there was no such a study that assessed the determinants of long acting contraceptive at national level. Therefore, this study aimed to identify to determinants of LACs methods utilization among reproductive age women in Ethiopia, 2013.

\section{Methods}

\subsection{Study Design and Setting}

Unmatched case control study design was conducted from February to June, 2013 using Ethiopian Demographic and Health Surveys (EDHS) 2011 dataset. Ethiopia has a total population of about 85 million with annual growth rate of $2.6 \%$. Currently, the country has a federal system of governance with nine regional states and two chartered cities, the national capital Addis Ababa and Dire Dawa (20). The recently implemented Business Process Reengineering (BPR) of the health sector has introduced three tire systems of health care delivery in Ethiopia. The first tier is the district health system comprised of a primary hospital (to cover $60,000-100,000$ people), health centers ( 1 to 15,000 - 25,000 population) and their Health Posts (1 to 3,000 5,000 population) connected to each other by a referral system forming a Primary Health Care Unit (PHCU). The PHCU provides comprehensive, integrated and community-based preventive and basic curative services. District Hospitals functions as a referral and training center for ten PHCUs. The second tier is a General or Zonal Hospital which provides specialist services and trainings. It serves to an average population of 1-1.5 million people; and the third tier is a Specialized Hospital providing comprehensive specialist services, and in some instances serve as centers for research, post basic training and covering an average population of 3.5-5 million peoples (19).

\subsection{Data Source}

Data was obtained from the 2011 EDHS. The EDHS is a periodic and national cross-sectional survey administered at the household level. It was carried out under the guidance of the Ministry of Health (MOH) and was implemented by the Central Statistical Agency (CSA) and United States Agency for International Development (USAID). Three EDHSs were conducted in Ethiopia, in 2000, 2005 and 2011 (16-18). The 2011 EDHS is part of the worldwide major DHS project designed to produce representative estimates for the country as a whole. The overall aim of this EDHS was to provide up to dated information on marriage, fertility, family planning, reproductive health, child health, and HIV/AIDS based on a large or representative samples $(18,21,22)$.

Cases: A women, who or her partner were using one of LACs (IUD, Implant, female or male sterilization) as a method of contraception. 
Controls: A women who were not using any method of contraception at the time of the survey.

\subsection{Sample Size Determination}

The sample size was calculated using EPI info version 3.5.3.for unmatched case-control study design. Based on the assumption that, desire for no more children is significant predictors of LACs utilization, the level of significance $(\alpha)=$ 0.05 , the power of the test $(1-\beta)=80 \%$, the case to control ratio(r) $=1: 4$, the proportion of exposure among controls (P1) $=59.7 \%$, the proportion of exposure among cases $(\mathrm{P} 2)=46.3 \%$ and $\mathrm{OR}=2.5$ (23). The final sample size calculated using the given assumptions gave 144 cases and 572 controls and a total of 716. Since increasing sample size helps to increase the power of the study and the total number of cases was manageable for this research, all the cases (364) and using computer generated random number, 1456 a randomly selected sample of controls with 1:4 cases to controls ratio were included in the study.

\subsection{Data Extraction and Management}

The desired data for this study was extracted from 2011 EDHS data set carefully based on the proposed study objectives. Questionnaire was used for the simplicity of data extraction process. Incomplete data were excluded before sampling procedure.

The newly created data set consists of all cases, randomly selected controls and an explanatory variable was created. Carefully extracted data was checked for its completeness. Then it was transformed, edited and recoded using SPSS data editor command.

\subsection{Data Analysis Procedures}

The created data set in SPSS version 16.0 were prepared for analysis. Variables were defined, categorized, transformed and recoded. Cross tabulation was used to calculate frequencies and proportions of cases and controls. The results were presented in the form of tables, figures, and summary statistics. Binary and multiple logistic regressions were used to assess the association of various determinant factors with LACs. Bi-variate analysis with crude odds ratio with 95\% CI was used to identify presence of association between independent variables and LACs use. Multivariable logistic regression analysis was done to control the possible confounding effects of variables. In a multiple logistic regression analysis all variables that were found significant at $p$-value of 0.25 and $95 \%$ $\mathrm{CI}$ in the bi-variate analysis were entered into the model and a backward step wise method was used. Variables which were significant at p-value 0.05 level and $95 \%$ CI were considered to be the determinant factors of LACs. An adjusted odds ratio with $95 \%$ CI was used for those variables which were found to be determinant factors of the use of long acting contraceptive methods.

\subsection{Ethical Consideration}

Ethical clearance for this study was obtained from Ethical Review Board of University of Gondar before starting the actual work. Online permission was obtained from web site www.measure DHS project to use the 2011 EDHS dataset for this study.

\section{Results}

\subsection{Socio-Demographic Characteristics of Participants}

Table 1. Socio-demographic characteristics of study participants, Ethiopia, 2013.

\begin{tabular}{|c|c|c|c|}
\hline Variable & Categories & Cases & Controls \\
\hline \multirow{2}{*}{ Residence } & Rural & $218(59.9 \%)$ & $1225(84.1 \%)$ \\
\hline & Urban & $146(40.1 \%)$ & $231(15.9 \%)$ \\
\hline \multirow{4}{*}{ Religion } & Orthodox & $210(57.7 \%)$ & $467(32.1 \%)$ \\
\hline & Protestant & $68(18.7 \%)$ & $233(16.0 \%)$ \\
\hline & Muslim & $80(22.0 \%)$ & $705(48.4 \%)$ \\
\hline & Other $^{a}$ & $6(1.6 \%)$ & $51(3.5 \%)$ \\
\hline \multirow{2}{*}{ Marital status } & Married & $322(88.5 \%)$ & $1376(94.5 \%)$ \\
\hline & Living with partner & $42(11.5 \%)$ & $80(5.5 \%)$ \\
\hline \multirow{5}{*}{ Wealth index } & Poorest & $34(9.3 \%)$ & $507(34.8 \%)$ \\
\hline & Poorer & $58(15.9 \%)$ & $243(16.7 \%)$ \\
\hline & Middle & $55(15.1 \%)$ & $265(18.2 \%)$ \\
\hline & Richer & $57(15.7 \%)$ & $203(13.9 \%)$ \\
\hline & Richest & $160(44.0 \%)$ & $238(16.3 \%)$ \\
\hline \multirow{3}{*}{ Women educational status } & No education & $186(51.1 \%)$ & $1079(74.1 \%)$ \\
\hline & Primary & $111(30.5 \%)$ & $313(21.5 \%)$ \\
\hline & $>=$ Secondary & $67(18.4 \%)$ & $64(4.4 \%)$ \\
\hline \multirow{2}{*}{ Working status } & No & $189(51.9 \%)$ & $1046(71.8 \%)$ \\
\hline & Yes & $175(48.1 \%)$ & $410(28.2 \%)$ \\
\hline \multirow{3}{*}{ Person who usually decide on respondents health care } & Partners alone & $63(17.3 \%)$ & $439(30.2 \%)$ \\
\hline & Women alone & $68(18.7 \%)$ & $235(16.1 \%)$ \\
\hline & Jointly & $233(64.0 \%)$ & $782(53.7 \%)$ \\
\hline
\end{tabular}

$\mathrm{a}=$ others religion includes catholic, traditional and pagans 
The total numbers of study participants who were included in this analysis were 1820; 364 cases and 1456 controls. The mean age of cases and controls were $32 \pm 7$ and $31 \pm 9$, respectively. Two hundred eighteen $(59.9 \%)$ of the cases and $1225(84.1 \%)$ of the controls were sampled from rural areas. Large proportions of cases were Orthodox Christian followers $210(57.7 \%)$. The majority of cases $322(88.5 \%)$ and controls $1376(94.5 \%)$ were married. Thirty four $(9 \%)$ of cases and 507 $(34.8 \%)$ of controls were categorized in the lowest wealth quintile. The smallest proportion of cases $67(18.4 \%)$ and $64(4.4 \%)$ controls have secondary and above level of education. Working women at the time of the survey accounts $175(48.1 \%)$ of cases and $410(28.2 \%)$ of controls. Sixty three $(17 \%)$ of cases and $439(30 \%)$ of controls have no power to decide for their own health care [Table 1].

\subsection{Reproductive and Service Related Characteristics of Respondents}

Thirty two percent of cases and controls have more than four living children. More than half of 199(54.7\%) cases and $432(29.7 \%)$ of controls have no desire for next children. Exposed to family planning message, at least by one of the medias accounts 198(54.4\%) of cases and 393(27.0\%) controls. Three hundred seventeen $(87.1 \%)$ of cases and $1271(87.3 \%)$ of controls have no history of terminated pregnancy. Moreover, 256(70.3\%) of cases and 1213(83.3\%) of controls were not visited by Health Extension Workers or Voluntary Community Health Workers in the last 12 months before the implementation of the survey [Table 2].

Table 2. Reproductive and service related characteristics of study participants, Ethiopia, 2013.

\begin{tabular}{|c|c|c|c|}
\hline Variables & Categories & Cases & Controls \\
\hline \multirow{4}{*}{ Number of living children } & Have no children & $10(2.7 \%)$ & $171(11.7 \%)$ \\
\hline & Have $1-2$ children & $124(34.1 \%)$ & $407(28.0 \%)$ \\
\hline & Have $3-4$ children & $112(30.8 \%)$ & $412(28.3 \%)$ \\
\hline & More than four children & $118(32.4 \%)$ & $466(32.0 \%$ \\
\hline \multirow[t]{2}{*}{ Fertility preference } & Undecided & $9(2.5 \%)$ & $44(3.0 \%)$ \\
\hline & Want no more & $199(54.7 \%)$ & $432(29.7 \%)$ \\
\hline \multirow{2}{*}{ Exposed to FP message on medias } & No & $166(45.6 \%)$ & $1063(73.0 \%)$ \\
\hline & Yes & $198(54.4 \%)$ & $393(27.0 \%)$ \\
\hline Ever had a terminated pregnancy & No & $317(87.1 \%)$ & $1271(87.3 \%)$ \\
\hline \multirow{2}{*}{ Visited by HEW/VCHW in last 12 months } & No & $256(70.3 \%)$ & $1213(83.3 \%)$ \\
\hline & Yes & $108(29.7 \%)$ & $243(16.7 \%)$ \\
\hline
\end{tabular}

Among the modern contraceptive methods, implant was known by $98.1 \%$ of the cases and $54.7 \%$ of the controls followed by female sterilization, IUD and male sterilization [Figure 1].

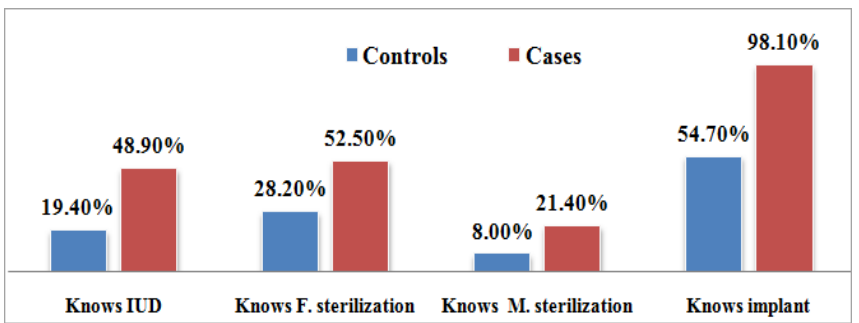

Figure 1. Knowledge of long acting contraceptives among cases and controls, Ethiopia, 2013.

\subsection{Factors Associated with Long Acting Contraceptive Use}

\subsubsection{Socio-Demographic Determinants}

Women who live with partners were 1.9 times [AOR
$(95 \% \mathrm{CI})=1.9(1.2,3.0))$ more likely to use LACs than married women. Household wealth index found to be predictors of LACs use. Those women who were living in the highest household wealth index were 4.8 times [AOR $(95 \% \mathrm{CI})$ $=4.8(3.0,7.0)]$ more likely to use LACs than women who live in the lowest household wealth index. Women's level of education also became an important determinant of LACs use, women who had secondary and above level of education were 3 times $[$ AOR $(95 \% \mathrm{CI})=3(1.5,5.0)]$ more likely to use LACs than non-educated women. Regarding to working status of women, working women were 1.7 times $[\mathrm{AOR}(95 \% \mathrm{CI})=1.7$ $(1.3,2.2)]$ more likely to use LACs than not working women. Decisions about respondent's health care also determine LACs use. Women who decide jointly about their health care were 1.4 times $[\mathrm{AOR}(95 \% \mathrm{CI})=1.4(1.1,2.0)]$ more likely to use LACs than women whom their husband decides alone [Table 3]. 
Table 3. Bi-variable and Multivariable analysis of determinants of LACs use in Ethiopia, 2013.

\begin{tabular}{|c|c|c|c|c|c|}
\hline Variables & Categories & Cases & Controls & Crude OR & Adjusted OR \\
\hline \multirow{3}{*}{ Age } & $15-24$ & 51 & 365 & 1 & \\
\hline & $25-34(1)$ & 159 & 570 & $1.99(1.42,2.81)$ & \\
\hline & $>=35(2)$ & 154 & 521 & $2.12(1.50,2.98)$ & \\
\hline \multirow{2}{*}{ Residence } & Rural & 218 & 1225 & 1 & \\
\hline & Urban & 146 & 231 & $3.55(2.76,4.57)$ & \\
\hline Marital status & Married & 322 & 1376 & 1 & \\
\hline \multirow{5}{*}{ Wealth index } & Lowest & 34 & 507 & 1 & \\
\hline & Second & 58 & 243 & $3.56(2.27,5.59)$ & $3.1(1.9,5.0)$ \\
\hline & Middle & 55 & 265 & $3.09(1.97,4.87)$ & $2.4(1.5,3.9)$ \\
\hline & Higher & 57 & 203 & $4.19(2.66,6.59)$ & $2.7(1.7,4.4)$ \\
\hline & Highest & 160 & 238 & $10(6.71,14.97)$ & $4.8(3.0,7.0)$ \\
\hline \multirow[b]{2}{*}{ Educational status } & No education & 186 & 1079 & 1 & \\
\hline & Primary & 111 & 313 & $2.06(1.58,2.69)$ & \\
\hline \multirow{2}{*}{ Women working status } & Not working & 189 & 1046 & 1 & \\
\hline & Working & 175 & 410 & $2.36(1.87,2.99)$ & $1.7(1.3,2.2)$ \\
\hline \multirow{3}{*}{$\begin{array}{l}\text { Person who decide on } \\
\text { respondents health care }\end{array}$} & Husband alone & 63 & 439 & 1 & \\
\hline & Respondents alone & 68 & 235 & $2.02(1.38,2.94)$ & \\
\hline & Jointly & 233 & 782 & $2.08(1.54,2.81)$ & $1.4(1.1,2.0)$ \\
\hline
\end{tabular}

\subsection{Reproductive and Service Related Determinants}

Numbers of living children was found to be strong predictors of LACs use. Women who have more than four children were 5.8 times $[\mathrm{AOR}(95 \% \mathrm{CI})=5.8(2.7,12.0)]$ more likely to use LACs compared to women who have no children. Moreover, women who have no desire for next children were 2.5 times $[\mathrm{AOR}(95 \% \mathrm{CI})=2.5(2.0,3.4)]$ times more likely to use LACs than women who want another children. Similarly,
Women who were exposed to family planning message on radio, $\mathrm{TV}$, news paper or magazine in the past 12 months before the survey were 1.5 times [AOR $(95 \% \mathrm{CI})=1.5(1.1$, 2.00)] more likely to use LACs than non-exposed counter parts. In addition, women who were visited by FP worker were also 1.8 times $[\mathrm{AOR}(95 \% \mathrm{CI})=1.8,(1.4,2.5)]$ more likely to use LACs than those not visited by FP workers [Table 4].

Table 4. Bi-variable and multivariable analysis of cases and controls by their reproductive and service related characteristics of women, Ethiopia, 2013.

\begin{tabular}{|c|c|c|c|c|c|}
\hline Variables & Categories & Cases & Controls & Crude OR & Adjusted OR \\
\hline \multirow{4}{*}{ Fertility preference } & Want another & 156 & 980 & 1 & \\
\hline & Undecided & 9 & 44 & $1.29(0.61,2.7)$ & \\
\hline & Want no more & 199 & 432 & $2.8(2.8,3.7)$ & $2.5(2.0,3.4)$ \\
\hline & Have no children & 10 & 171 & 1 & \\
\hline \multirow{3}{*}{ Number of living children } & Have $1-2$ & 124 & 407 & $5.2(2.7,10.2)$ & $5.5(2.7,11)$ \\
\hline & Have 3-4 & 112 & 412 & $4.6(2.4,9.1)$ & $6(3.0,12.0)$ \\
\hline & Have $>4$ & 118 & 466 & $4.3(2.2,8.4)$ & $5.8(2.7,12.0)$ \\
\hline \multirow{2}{*}{ Ever had terminated pregnancy } & No & 317 & 1271 & 1 & \\
\hline & Yes & 47 & 185 & $1.0(0.72,1.4)$ & \\
\hline \multirow{2}{*}{ Exposed to FP message on medias } & No & 166 & 1063 & 1 & \\
\hline & Yes & 198 & 393 & $3.2(2.5,4.1)$ & $1.5(1.1,2.00)$ \\
\hline \multirow{2}{*}{ Visited by HEW/VCHW } & No & 256 & 1213 & 1 & \\
\hline & Yes & 108 & 243 & $2.1(1.6,2.7)$ & $1.8(1.4,2.5)$ \\
\hline
\end{tabular}

\section{Discussions}

The purpose of this study was to identify determinants of LACs use among reproductive age women based on EDHS 2011 data set. One of the independent variable which has an impact for LACs use in this study is marital status. The current study revealed that women who live with their partners were more likely to use LACs than women who have formal marriage. This may be due to the fact that in most parts of Ethiopia giving birth before marriage is considered to be socially unacceptable action by the society. The other explanation may be related with economic reason. If they are not married, the source of the household economy comes from one side only. As a result, she may not afford the cost of rearing children. Hence, these may force unmarried women to use long term and effective methods of contraceptives compared to their married counterparts.

The other most important variable which has an impact on many of reproductive and health related outcome is education (24). Likewise, this study showed the importance of education 
to use LACs. Women with secondary and higher level of education were more likely to use LACs than uneducated women. This finding is in line with the result of case control study done in Addis Ababa to identify factors associated with IUD use (25). Similarly, it was supported by the result found from secondary data analysis of Indonesian DHS (26); women with higher education were more likely to use long-term methods than those who were uneducated.

The reasons why education is associated with LACs use is that better educated women may have better understanding about the importance of FP for themselves and for their family. Similarly better educated women may be more knowledgeable about the available options. Moreover, they may have a power to decide about their own health care.

Household wealth index has significant association with LACs utilization. Women who had second and above household wealth index were more likely to use LACs. It may be due to that this women having second and above wealth index being able to afford the transportation and procedural cost of LACs method. In addition this might be due to strong association between wealth and education in Ethiopia. Almost all women with secondary and higher education live in the wealthiest households. On the contrary, a large majority of households with the lowest wealth index consist of women with no or low education level (24).

The other significant predictor for LACs use in this study was numbers of living children. Women who have one or more children were more likely to use LACs than those women who have no children. This result was supported by the result of research done in France from multivariable analysis of trends and barriers of LARCs use study. It was revealed that, women who have more than two children were more likely to use LARCs than women who have no children (27). This may be due to women who have children may reach their preferred family size. Therefore, these women were more likely to abandon pregnancy by using more effective methods.

Future desire of fertility also determines utilization of LACs. Women who have a desire to stop fertility were more likely to use LACs than those women who want another child. This finding was supported by a research done in Indonesia and Ethiopia (Addis Ababa and Mekelle) $(23,25,26)$. Findings from the above studies revealed that women who do not want any more children were more likely to use LACs than women who want other children. This may be due to the fact that women who want to stop fertility may choose long term and effective methods from the available options.

This study also showed the importance of women exposure to FP message thorough Medias for the utilization of LACs. Women who had exposure to FP message on either of the Medias such as radio, TV, news paper/ magazine in the past few months before the survey were more likely to use LACs than non exposed counter parts. This result is in line with the secondary data analysis of Indonesian DHS (26): i.e. women who have exposure to FP message were more likely to use LACs than women who have no any exposure to FP message on Medias. This association may be explained by the importance of awareness creation using mass media. It can reach many peoples, and this helps to reduce myths and miss-conception about long term contraceptives in the society.

Another factor which has an impact on LACs use in this study was visited by HEW/VCHW or other FP workers in the past 12 months before the survey. Women who were visited by FP worker were more likely to use LACs than non visited counter parts. Similar result was found from secondary data analysis of Indonesia DHS data [24]. This may be due to HEW/VCHW or other FP workers provide appropriate information about the available contraceptive methods and they may select the most effective one.

\section{Limitation of the Study}

Since, this study use secondary data so it has its own limitation. First this study did not include all potential variables which can influence LACs use due to missed value and un- availability of the data in EDHS 2011data set. For example, variables related to service providers, access and suppliers. Because all women which have incomplete data set were excluded from the analysis, the result may be affected due to difference in the characteristic of women with full response and those women with in complete response. In addition the trustfulness of the data was based on study subjects, data collectors and data editors. Similarly, this study may not show the current situations of LACs utilization in Ethiopia. Finally, because of scarcity of studies which use DHS variables, the comparison in discussion part limited too few numbers of studies.

\section{Conclusion}

The result of this study showed that most of the independent variables included in this study were found to be independent and significant predictors for LACs use. Secondary and above level of education and working status of women, being visited by family planning workers in the last 12 months, exposure to family planning messages, number of living children, increasing household wealth index and wanting no more children have positive association on LACs utilization. However, this study revealed that being married women were negatively associated with LACs use.

\section{Recommendations}

In light of the research findings, LACs utilization in Ethiopia is influenced by many factors. In order to enhance the uptake of these methods the following recommendations were forwarded. Ministry of health and NGOs continue their effort to provide un-interrupted education about LACs using various methods such as health education, peer promotion and mass media communication in advance. In addition, considering programs that target women who live in the lowest household wealth index is important. HEW/VCHW and FP workers should dedicate their time and efforts to encourage married woman to use LACs. Everybody should encourage women to reach up to secondary and above level of education. 
Conducting another study with primary data using either quantitative, qualitative or both study approaches including variables from provider and supply side to have better result for planning and taking appropriate actions on it is recommended.

\section{Acknowledgement}

We would like to acknowledge Amhara Regional Health Beauro for the financial support to conduct this study. We are highly incepted to extend our thanks MEASURE DHS data archive owners for their permission to use Ethiopian 2011 datasets. We want express our greatest thanks to all study participants.

\section{References}

[1] Vlassoff M, Sundaram A, Bankole A. Benefits of Meeting the Contraceptive Needs of Ugandan Women, In Brief, New York, USA. Edited by Haley Ball, Guttmacher Institute, 2009, Series No. 4.

[2] US Agency for International Development (USAID). Using Quantification to Support Introduction and Expansion of Long-Acting and Permanent Methods of Contraception. USA: USAID|Deliver Project, Engender Health/The RESPOND Project October, 2010.

[3] Jacobstein R, Stanley H. Contraceptive implants: Providing better choice to meet growing family planning demand. Global Health Science and Practice, New York, USA, August 14, 2013, 1(1), 11-17. http://dx.doi.org/10.9745/GHSP-D-13-00003.

[4] US Agency for International Development (USAID). Long Acting and Permanent Methods of Contraception: Meeting Clients' Needs: Issue Brief. August 2006.

[5] Family Health International (FHI), Long-Acting and Permanent Methods:Highlights of the Contraceptive and Reproductive Health Technologies Research and Utilization Program, 2005-2010. 2010.

[6] Sundrama A, Vlassoff M, Bankole A, Gebrehiwote Y. Benefits of Meeting the Contraceptive Needs of Ethiopian Women: In Brief, New York. Guttachmar institute July, 2010.

[7] USAIDS/FHI. Addressing Unmet Need for Family Planning in Africa, The Case for Long-Acting and Permanent Methods, 2007.

[8] USAID. Long-Acting and Permanent Methods of Contraception: Meeting Clients' Needs. Issue Brief. 2006.

[9] Janowitz B, Gmach R, Otterness C. The Commercial Sector's Role in Providing Long-Acting and Permanent Methods. Bethesda, MD: Private Sector Partnerships-One Project/Abt Associates Inc. 2006.

[10] Thoai D. Ngo ON, Kate Reiss, Shreya K. Pereira. Expanding long-acting and permanent contraceptive use in sub-Saharan Africa to meet FP2020 goals. Marie stops international. 2013.

[11] Sedgh G, Hussain R. Women with an unmet need for contraception in developing countries and their reasons for not using a method Akinrinola Bankole and Susheela Singh Occasional Report 2007; No. 37. Occasional Report:1-80.
[12] Westoff, Charles F. New estimates of unmet need and the demand for family planning. DHS Comparative Reports No. 14. Calverton, Md: Macro International Inc. 2006.

[13] Blumenthal PD, Voedisch A, Gemzell-Danielsson K. Strategies to prevent unintended pregnancy: increasing use of long-acting reversible contraception. Human Reproduction Update 2011;17:121-37.

[14] Van Lith LM, Yahner M, Bakamjian L, Women's growing desire to limit births in sub-Saharan Africa: meeting the challenge. Available http://www.ghspjournal.org/cgi/doi/10.9745/GHSP-D-12-000 36. Accessed Oct 21, 2013. Global Health: Science and Practice. 2013;1(1):97-107.

[15] Federal Ministry of Health. National Guideline for Family Planning Services in Ethiopia Addis Ababa: Ministry of Health, October, 2011.

[16] Central Statistical Agency. Ethiopia Demographic and Health Survey 2000. Addi Ababa Ethiopia: 2001.

[17] Central Statistical Agency. Ethiopia Demographic and Health Survey 2005 Addis Ababa Ethiopia: 2006.

[18] Central Statistical Agency. Ethiopia Demographic and Health Survey 2011. Addis Ababa, Ethiopia: March 2012

[19] Federal Ministry of Health. Health Sector Development Programme IV 2010/11 - 2014/15, Addiss Ababa, Ethiopia, October 2010.

[20] FDRE, Constitution of the Federal Democratic Republic of Ethiopia (FDRE), Addis Ababa, Ethiopia,1995.

[21] Oscar SR, Rojas G. Guide to DHS STATISTICS, Demographic and Health Surveys Methodology. ORC Macro Calverton, Maryland 2006.

[22] USAID. Standard recode manual for DHS 5. Demographic and Health Surveys, USAID, August 22, 2012, Version 1.

[23] Mussie A, Teferra B, Tizita T. Factors associated with utilization of long acting and permanent contraceptive methods among married women of reproductive age in Mekelle town, Tigray Region, north Ethiopia. BMC Pregnancy and Childbirth Research. 2012; 12 (6).

[24] Central Statistical Agency. The Impact of Education on Health Outcomes; A new look at data from the 2005 Ethiopia Demographic and Health Survey, 2006.

[25] Anley H, Misganaw F. Demand for long acting and permanent contraceptive methods and associated factors among family planning service users in Batu Town, East Showa, Ethiopia, 2009.

[26] Rahayu R, Utomo I, McDonald P, Contraceptive Use Pattern among Married Women in Indonesia; the International Conference on Family Planning; Uganda: Research and Best Practices, 2009, November 15-18.

[27] Moreau C, Bohet A, Mireille Le G, Bajos N: Trends and barriers of use of long acting reversible contraception in France: Results from a population based survey. 